\title{
A LIGA ACADÊMICA DE DIREITO CONSTITUCIONAL DO NORTE DE MINAS GERAIS
}

\author{
THE ACADEMIC LEAGUE OF CONSTITUTIONAL LAW FROM NORTH OF \\ MINAS GERAIS (BRAZIL)
}

\section{LA LIGA ACADÉMICA DEL DERECHO CONSTITUCIONAL EN EL NORTE DE MINAS GERAIS}

\section{WELLEM RIBEIRO DA SILVA}

Mestranda em Desenvolvimento Social pela Unimontes, Montes Claros, MG, Brasil; Especialista em Didática e Docência do Ensino Superior pela Unimontes, Advogada, Professora do curso de Direito da FAVENORTE, Mato Verde, MG, Brasil. E-mail: wellemribeiro@yahoo.com.br

\section{FÁBIO FONSECA TELLES}

Especialista em Direito Empresarial, Advogado, Professor do curso de Direito da FAVENORTE, Mato Verde, MG, Brasil. fabio.ffab.adv@hotmail.com

\section{NUBIA BRUNO DA SILVA}

Mestre em História pela Unimontes, Montes Claros, MG, Brasil, Advogada, Professora do curso de

Direito da FAVENORTE, Mato Verde, MG, Brasil. nubiabsilvaadv@ hotmail.com

\section{CLAUDINEIA TEIXEIRA LIMA}

Acadêmica do curso de Direito da Faculdade FAVENORTE, Mato Verde, MG, Brasil. claudineiat16@gmail.com

\section{MURILO ANTUNES DA MATA}

Acadêmico do curso de Direito da Faculdade FAVENORTE, Mato Verde, MG, Brasil. murilomamonas@hotmail.com

\section{MARLI COSTA DURÃES}

Acadêmica do curso de Direito da Faculdade FAVENORTE, Mato Verde, MG, Brasil. marliduraes@hotmail.com 
SILVA, W. R. da; TELlES, F. F.; SILVA, N. B. da; LIMA, C. T.; MATA, M. A. da; DURÃES' M. C.

"A liga acadêmica de direito constitucional do norte de minas gerais"

\title{
Resumo
}

Repensar o ensino e a educação no Brasil de modo geral é imperativo visto que o paradigma no Brasil ainda é de um ensino com bases tradicionais. No ensino jurídico isso não é diferente, mostrando-se frequentemente formalista e com aprendizagem compartimentada pautada na acumulação de informações. A Extensão Universitária vive um momento de reconhecimento crescente como um verdadeiro pilar de formação intelectual na academia. Nesse contexto, o presente artigo pretende abordar e criticizar conceitos e aspectos formativos da atividade extensionista para um curso de Direito, mostrando a experiência exitosa da primeira liga acadêmica de Direito Constitucional na região extrema do Norte de Minas Gerais, Brasil, fundada em uma instituição privada que representa a única opção de formação para uma grande população local e de cidades vizinhas, em região cercada por desafios de acesso, como o transporte e rodovias, além de limitações de tempo e finanças da maior parte dos estudantes. Defende-se no texto a possibilidade de um outro olhar para o ensino aprendizagem, pautado no discente como autor principal do processo.

Palavras-chave: Liga acadêmica. Direito constitucional. Extensão universitária.

\begin{abstract}
Rethinking teaching and education in Brazil, in general, is imperative since the paradigm in Brazil is still one of teaching with traditional bases. In legal education, this is no different, being often formalistic and with compartmentalized learning based on the accumulation of information. University Extension is experiencing a moment of increasing recognition as a true pillar of intellectual training in academia. In this context, the present article intends to approach and criticize concepts and formative aspects of the extension activity for a Law course, showing the successful experience of the first academic league of Constitutional Law in the extreme North region of Minas Gerais, Brazil, founded in a private institution which represents the only studding option for a large local population and neighboring cities, in a region surrounded by access challenges, such as transport and highways, in addition to time and finances limitations of most students. The text defends the possibility of another look at teaching and learning, based on the student as the main author of the process.
\end{abstract}

Keywords: Academic league. Constitutional law. University extension.

\section{Resumen}

Es imperativo repensar la enseñanza y la educación en Brasil en general, ya que el paradigma en Brasil sigue siendo el de enseñar con bases tradicionales. En educación legal, esto no es diferente, se muestra a menudo formalista y con un aprendizaje compartimentado basado en la acumulación de información. University Extension está experimentando un momento de creciente reconocimiento como un verdadero pilar de la formación intelectual en la academia. En este contexto, el presente artículo pretende abordar y criticar conceptos y aspectos formativos de la actividad de extensión para un curso de Derecho, mostrando la experiencia exitosa de la primera liga académica de Derecho Constitucional en la región del extremo norte de Minas Gerais, Brasil, fundada en una institución privada. que representa la única opción de capacitación para una gran población local y ciudades vecinas, en una región rodeada de desafíos de acceso, como el transporte y las carreteras, además de las limitaciones de tiempo y finanzas de la mayoría de los estudiantes. El texto defiende la posibilidad de otra mirada a la enseñanza y el aprendizaje, basada en el alumno como autor principal del proceso.

Palabras clave: Liga académica. Derecho constitucional. Extensión Universitaria. 
SILVA, W. R. da; TELLES, F. F.; SILVA, N. B. da; LIMA, C. T.; MATA, M. A. da; DURÃES' M. C.

"A liga acadêmica de direito constitucional do norte de minas gerais"

RBPG, Brasília, v.16, n.35, 2020.

Experiências 
SILVA, W. R. da; TELlES, F. F.; SILVA, N. B. da; LIMA, C. T.; MATA, M. A. da; DURÃES' M. C.

"A liga acadêmica de direito constitucional do norte de minas gerais"

\section{INTRODUÇÃO}

A Extensão Universitária vive um momento de reconhecimento crescente no Brasil, passando a compor com maiores critérios os índices de avaliação institucional do IPEA e compondo meta específica de inclusão nos projetos pedagógicos dos cursos, de forma que se prevê a obrigatoriedade do cumprimento de no mínimo 10\% (dez por cento) dos créditos exigidos para a formação do profissional no ensino superior em ações de extensão universitária (MINISTÉRIO DA EDUCAÇÃO, 2018). Nesse sentido impulsiona-se a conscientização de que Extensão Universitária deva ser parte um pilar da formação acadêmica. A Extensão Universitária, ao estimular o contato entre o ensino universitário e a comunidade acadêmica e não acadêmica que vive em seu entorno, cria o potencial de contribuir com a capacidade de análise crítica e aplicabilidade dos conhecimentos obtidos em salas de aula, ao mesmo tempo em que abre portas para pesquisas científicas visando responder aos problemas que emergem durante a aplicação da ciência. Segundo referências nacionais promovidas pelo Fórum Nacional de Pró-Reitores de Extensão das Instituições de Ensino Superior Públicas Brasileiras, a importância da Extensão na formação acadêmica e social parte de suas características norteadoras, a saber: interação dialógica, interdisciplinaridade e interprofissionalidade, indissociabilidade Ensino-Pesquisa-Extensão, impacto na formação do estudante e impacto e transformação Social (FORPROEX, 2012).

Repensar o ensino e a educação no Brasil de modo geral é imperativo visto que o paradigma no Brasil ainda é de um ensino com bases tradicionais. No ensino jurídico isso não é diferente trata-se de um ensino tradicional, formalista com uma aprendizagem compartimentada pautada na acumulação de informações, destinando a formação do operador do Direito para o enfrentamento de conflitos interindividuais, ofuscando condições de enfrentar/atender as demandas de uma sociedade repleta de conflitos supraindividuais (STRECK, 2011).

Nesse contexto, o presente artigo pretende relatar através de estudo de caso uma experiência exitosa de extensão em Direito, cuja base se dá a partir de condução aprimorada de uma liga acadêmica orientada adequadamente a abranger a relação extraclasse pautada na indissociabilidade "Ensino, Pesquisa e Extensão". 
SILVA, W. R. da; TELlES, F. F.; SILVA, N. B. da; LIMA, C. T.; MATA, M. A. da; DURÃES' M. C.

"A liga acadêmica de direito constitucional do norte de minas gerais"

\section{O ÊXITO EXTENSIONISTA LIGA ACADÊMICA DE DIREITO CONSTITUCIONAL - LADC}

\subsection{Contexto gerador da primeira liga acadêmica de direito constitucional do norte de minas}

Juan Ramón Capella chama atenção para as limitações de ensino quando se restringe a experiência naquilo que se conhece como "aprendizagem de manutenção", onde os conteúdos são trabalhados com os estudantes em cima de problemas práticos pré-concebidos e com desfechos limitados e já conhecidos pré-elaborados. O avanço no processo de aprendizagem é vislumbrado quando se alia a possibilidade de "aprendizagem inovadora", que "consiste em aprender a enfrentar problemas e situações distintas dos conhecidos pelos professores, e a achar soluções inéditas; e, secundariamente, consiste em solucionar problemas conhecidos com soluções melhores do que aquelas dadas" (CAPELLA, p. 26, 2011).

A Extensão Universitária pode ser vista como um processo educativo, cultural e científico, que articula o ensino e a pesquisa de forma indissociável possibilitando uma relação transformadora entre Universidade e sociedade. Acredita-se que essa relação possa enriquecer o processo pedagógico socializando o saber acadêmico com a participação da comunidade na vida acadêmica. Os resultados desse processo tem potencial de atingir não só os estudantes, mas também professores e comunidade, além de realimentar o ensino e ser fundamental para a pesquisa científica (SALGADO FILHO, 2007). Dessa forma, a partir de uma relação de cumplicidade criada em sala de aula entre um grupo de docentes e de acadêmicos que ansiavam por possibilidades ampliar as relações de aprendizagem, surgiu a ideia de criação da Liga acadêmica de Direito Constitucional (LADC), vinculada a coordenação do curso de Direito da Faculdade Verde Norte (FAVENORTE), campus Mato Verde-MG, e que representou o primeiro projeto de Extensão da instituição, cujo curso de Direito ainda estava em fase de reconhecimento.

A proposta de criação da LADC concretizou-se após manifesto generalizado de interesse dos acadêmicos no desenvolvimento de projetos de iniciação científica, voluntariamente ofertados nas disciplinas Direito Constitucional I e Direito Constitucional II pela professora Wellem Ribeiro da Silva que viria a ser a coordenadora docente de fundação da LADC. De um total de 59 estudantes das duas disciplinas, 18 mostraram interesse nas atividades investigativas extraclasse, ou seja, iniciação científica. $\mathrm{O}$ intuito desta iniciativa seria conduzir

RBPG, Brasília, v.16, n.35, 2020. 
SILVA, W. R. da; TELlES, F. F.; SILVA, N. B. da; LIMA, C. T.; MATA, M. A. da; DURÃES' M. C.

"A liga acadêmica de direito constitucional do norte de minas gerais"

trabalhos científicos de revisão de literatura com potencial de submissão ao Fórum de Ensino, Pesquisa, Extensão e Gestão da Universidade Estadual de Montes Claros, um evento regionalmente conhecido e respeitado. Percebendo o volume de reuniões que o grupo promovia para leitura de textos e definição de temas, surgiram as ideias de minicursos de metodologia e de constituição de uma liga acadêmica. Na verdade, a grande maioria dos acadêmicos não compreendiam o conceito de liga proposto pela professora, mas sabiam que isso viabilizaria encontros e novas oportunidades de aprendizado e produção acadêmica. A grosso modo seria uma possibilidade digna para aprimorar conhecimento e obter certificação.

As ligas acadêmicas são tradicionalmente reconhecidas como projetos de Extensão, pois incorporam os princípios do ensino, da pesquisa e da extensão, assumindo um caráter extracurricular com o intuito de complementar as atividades acadêmicas, através da abordagem de ações de natureza teórica e prática. As atividades teóricas são desenvolvidas através de aulas, seminários, apresentações de casos concreto de lides, análise e discussão de textos e realização de eventos científicos (SILVA; FLORES, 2015).

A finalidade da LADC seria propiciar reais investiduras para a consolidação e construção de conhecimentos científicos e desenvolvimento de atividades de ensino e extensão, bem como propiciar maior integração de docentes e discentes entre si e com a comunidade do entorno universitário, partindo de uma pedra fundamental do curso de Direito: o Direito Constitucional.

Professores de outras disciplinas foram convidados de forma que a composição final da liga se deu por três docentes além da coordenadora e 14 acadêmicos que estavam no grupo de iniciação científica. Sendo a primeira iniciativa docente na instituição em termos de projeto de Extensão oficial, imbuiu-se adicionalmente dos desafios de elaboração e proposição de toda uma estrutura documental que garantisse a institucionalização como projeto de Extensão: projeto de desenvolvimento e organização das ações, estatuto, editais de seleção, declarações de responsabilidade docente e discente e de isenção de custos à instituição (uma barreira indesejada e real). A documentação para a institucionalização da liga frente a faculdade foi elaborada em conjunto por professores e acadêmicos, assim como estatuto da mesma e a definição de encargos e responsabilidades de presidente, vice-presidente, diretor de comunicação, tesoureiro e secretário. Mais uma vez, essa iniciativa foi valiosa, pois era algo que até então não era parte dos planos institucionais, contribuindo com a organização do Plano 
SILVA, W. R. da; TELLES, F. F.; SILVA, N. B. da; LIMA, C. T.; MATA, M. A. da; DURÃES' M. C.

"A liga acadêmica de direito constitucional do norte de minas gerais"

de Extensão Institucional e tornando-se referencial para outros docentes e discentes do curso de Direito e de outros cursos. Como já afirmava o renomado professor Boaventura de Souza Santos:

\begin{abstract}
A extensão vai ter no futuro próximo um significado muito especial. No momento em que o capitalismo global pretende funcionalizar a universidade, e de fato, transformá-la numa vasta agência de extensão ao seu serviço, a reforma da universidade deve conferir uma nova centralidade às atividades de extensão, (com implicações no curriculum e nas carreiras dos docentes) e concebê-las de modo alternativo ao capitalismo global, atribuindo as universidades uma participação ativa na construção da coesão social, no aprofundamento da democracia, na luta contra a exclusão social e a degradação ambiental, na defesa da diversidade cultural. (SANTOS, 2004, p. 53)
\end{abstract}

A aprovação da LADC foi recebida com entusiasmo, concebida como a primeira no Norte de Minas na área do Direito Constitucional, e assim merecedora de uma cerimônia solene que consagrou sua fundação, algo que funcionou muito bem e veio a ser incorporado como prática sempre que novos integrantes ingressassem a partir dos processos seletivos vindouros (figura 1). A cerimônia basicamente segue rito de uma colação de grau, em menores proporções, havendo mesa solene composta por: diretor da faculdade, coordenador do curso de Direito, docentes membros da LADC, estudantes com cargos de liderança na LADC; todos com vestimentas formais e com registro em ata. Jamais se imaginava que a LADC atingiria tamanho potencial de integração acadêmica. Como na perspectiva de Paulo Freire, o processo de ensinoaprendizagem está intimamente associado à interatividade entre educadores e educandos (FREIRE, 2011).

Figura 1. Registro de membros da LADC em sua cerimônia de fundação. 


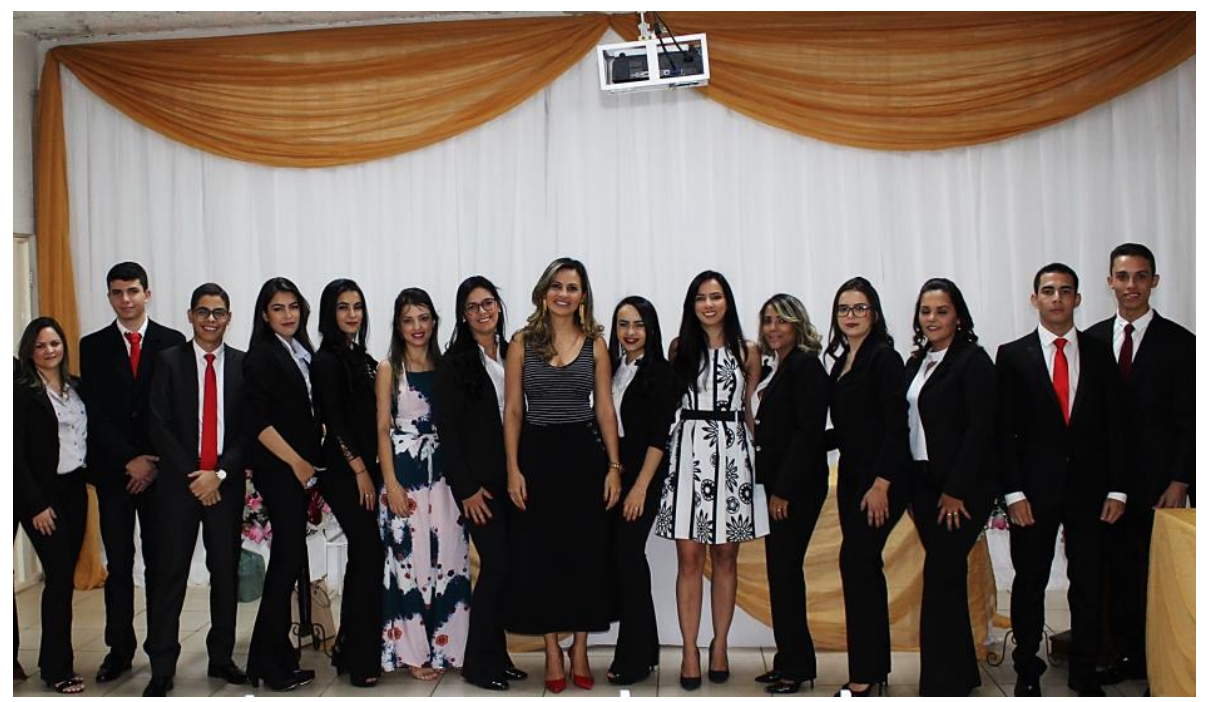

Fonte: Arquivo pessoal.

Em 22 de setembro de 2018 inaugura-se a LADC: a primeira Liga Acadêmica de Direito Constitucional do norte de Minas Gerais. Desde sua fundação estabelecia-se uma parcela obrigatória de agenda: encontros quinzenais presenciais mesclados com minicursos, oficinas, seminários sobre temas definidos em reuniões e organização de uma jornada acadêmica. A experiência se relata considerando os elementos qualitativos vivenciados, cabendo aqui registrar que os ligantes se tornavam visivelmente referenciais em estudos durante até mesmo as práticas convencionais de sala de aula, o que motivava outros discentes no desejo por ingresso na LADC e pela elaboração de novas oportunidades de Extensão.

\subsection{Enfrentando desafios}

O maior desafio a ser relatado aqui é a distância física entre docentes, discentes a faculdade, que se situa em um centro cercado por pequenas cidades que a viabilizam como possibilidade mais acessível de acesso ao ensino superior. Dos quatorze alunos fundadores da LADC, apenas três moravam em Mato Verde (MG), campus da faculdade de Direito. Os demais moravam em cidades próximas que variam entre 12 a 110 quilômetros, havendo grande parte dos trechos com estrada de terra. Muitos ainda vivenciavam a rotina de sair do trabalho e ir direto para a faculdade visto o curso ser noturno. Como reunir com esses acadêmicos que só estavam na faculdade a noite durante o horário da aula (19:20 às 22:30)? Como reunir durante o dia se os mesmos estavam em horário de trabalho? Como reunir aos sábados se muitas linhas de ônibus eram exclusivas para estudantes e restrita aos dias úteis? Tudo isso agravado ao fato 
SILVA, W. R. da; TELlES, F. F.; SILVA, N. B. da; LIMA, C. T.; MATA, M. A. da; DURÃES' M. C.

"A liga acadêmica de direito constitucional do norte de minas gerais"

de duas das professoras morarem em Montes Claros (215 km de Mato Verde) e uma morar em Janaúba ( $80 \mathrm{~km}$ de Mato Verde) as quais também viajavam para ministrar suas aulas.

A solução encontrada naquele momento foi deixar sábados pré-agendados nos quais as professoras revezariam a frequência e os estudantes lutariam com recursos próprios a medida do que conseguiam. Outra solução encontrada foi a realização de encontros via Skype e discussões via aplicativo whatsApp, utilizando assim as premissas do aprendizado a partir do suporte de "tecnologias digitais de informação e comunicação". Os aparelhos eletrônicos como celulares e tablets tornam-se cada vez mais potentes e proporcionam a conexão com redes facilitadoras de compartilhamento de assuntos científicos e que proporcionam comunicação rápida (PAULINO et al., 2018).

O segundo desafio que se destaca diz respeito às ocupações não acadêmicas dos alunos, os quais, em cerca de $90 \%$, dependiam de seus trabalhos remunerados do período diurno. Como disponibilizar de tempo para se dedicar as atividades da liga as quais não se encerravam apenas nos encontros mensais aos sábados? Não havia uma solução ideal para romper esta barreira, e os ligantes as enfrentavam da maneira que podiam com base no cronograma: trocavam turnos de trabalho, abriam mão dos períodos de recessos estendidos, negociavam com seus chefes um banco de horas, etc. Esse desafio foi enfrentado por cada um, que ao decorrer do semestre repensaram prioridades e fizeram escolhas.

Por fim, o terceiro e também importante desafio se deu pela falta de remuneração docente para este fim. A atividade de pesquisa e extensão nas faculdades e universidades privadas muitas vezes são bloqueadas por ausência de plano docente remunerado para estes fins, atributos que clamam a atenção dos eleitores brasileiros, que nem sempre observam a crescente precarização do trabalho docente e precarização do ensino superior (BOSI, 2007). O estudo clássico realizado pelo Núcleo de Pesquisas sobre Ensino Superior da Universidade de São Paulo há tempos aponta essa fragilidade do ensino superior brasileiro, trazendo à luz que “[e]m relação ao pagamento de outras atividades que não seja a aula efetiva, cerca de $10,0 \%$ dos docentes são remunerados para atividades de pesquisa, pouco mais de 8,0\% para extensão e quase 14,0\% para administração acadêmica." (LOBO, 2003, p.12). De fato, o texto identifica que a maioria das instituições de ensino superior avaliadas não se empenhou em infraestrutura e remuneração para incorporar ao quadro docente um perfil de professores que permaneçam na instituição além do tempo dedicado às aulas, consequentemente não possuem critérios de 
SILVA, W. R. da; TELLES, F. F.; SILVA, N. B. da; LIMA, C. T.; MATA, M. A. da; DURÃES' M. C.

"A liga acadêmica de direito constitucional do norte de minas gerais"

julgamento e acompanhamento de projetos de pesquisa e extensão. Os docentes envolvidos na LADC iniciaram essa atividade como voluntários, interessados em sua evolução profissional e alimentados pela paixão docente. $\mathrm{Na}$ exposição de resultado obtidos, tópico a seguir, demonstraremos o quanto esses alunos se envolverem com LADC, o quanto se dedicaram e ultrapassaram as barreiras físicas, financeiras, psicológicas e cronológicas que aqui foram expostas em dois resumidos tópicos.

\subsection{Os resultados obtidos}

A demonstração objetiva de resultados de ações é uma forma de se valorar e acompanhar o desenvolvimento de uma ação de Extensão, e se a mesma está cumprindo com os objetivos propostos. Apesar de a LADC ser um projeto de instituição privada, tomam-se emprestados aqui as formas de classificação das ações e alguns indicadores que são estabelecidos pelo Fórum de Pró-reitores de Extensão das Universidades Públicas Brasileiras, principalmente por serem de maior aplicabilidade nacional e úteis para estabelecer parâmetros e apontar horizontes globais (FORPROEX, 2012). Critérios "quantitativistas" ainda são ferramentas objetivas úteis para se comprovar a produção do trabalho docente e suas consequências, ainda que em um contexto de oferta voluntária.

A LADC classifica-se então como um projeto de pesquisa, que é um tipo de modalidade dentro da Extensão capaz de produzir cursos, eventos e prestações de serviços. A área temática que melhor a classifica é a "Direitos humanos e justiça" dentre as demais estabelecidas pelo FORPROEX, que são: Comunicação; Cultura; Educação; Meio Ambiente; Saúde; Tecnologia e Produção; Trabalho. Apesar disso, o Direito Constitucional trata da base que garante princípios fundamentais de uma sociedade organizada, apoiado no Brasil em uma "Constituição Cidadã", configurando-se como Direito Público fundamental por referir-se diretamente à organização e funcionamento do Estado, à articulação dos elementos primários do mesmo e ao estabelecimento das bases da estrutura política (SILVA, 2018). Assim, admitimos, de modo geral, que sendo o Direito Constitucional um tronco do qual nasce ou o qual dá fundamentação para as demais disciplinas jurídicas, a LADC atinge um vasto campo de atuação, sem restrições a ações que possam abraçar todas as áreas temáticas, que são: cultura, meio ambiente, saúde, tecnologia e produção e trabalho. Ou seja, premissas necessárias à entrega da dignidade da pessoa humana.

RBPG, Brasília, v.16, n.35, 2020. 
SILVA, W. R. da; TELLES, F. F.; SILVA, N. B. da; LIMA, C. T.; MATA, M. A. da; DURÃES' M. C.

"A liga acadêmica de direito constitucional do norte de minas gerais"

As tabelas 1 e 2 demonstram resultados quantitativos de 1 ano de experiência da

LADC.

Tabela 1. Demonstrativo de resultados quantitativos da LADC em seu $1^{\circ}$ ano de ações, não incluindo temáticas das reuniões quinzenais de orientações a discussões gerais.

\begin{tabular}{|c|c|c|c|c|c|}
\hline $\begin{array}{l}\text { Ações } \\
\text { desenvolvid } \\
\text { as }\end{array}$ & Referenciais da ação & $\begin{array}{l}\text { Carga } \\
\text { horária }\end{array}$ & $\begin{array}{l}\text { Total de } \\
\text { atendimento } \\
\text { s }\end{array}$ & $\begin{array}{l}\text { Público- } \\
\text { alvo }\end{array}$ & Local \\
\hline \multirow{3}{*}{$\begin{array}{l}\text { Cursos } \\
\text { presenciais }\end{array}$} & $\begin{array}{l}\text { Título: A escrita } \\
\text { científica (parte 1) } \\
\text { Tipo: presencial }\end{array}$ & 4 & 14 & $\begin{array}{l}\text { Acadêmic } \\
\text { os da } \\
\text { LADC }\end{array}$ & $\begin{array}{l}\text { Favenorte } \\
\text { campus } \\
\text { Mato } \\
\text { Verde } \\
(\mathrm{MG})\end{array}$ \\
\hline & $\begin{array}{l}\text { Título: A escrita } \\
\text { científica (parte 2) }\end{array}$ & 4 & 14 & $\begin{array}{l}\text { Acadêmic } \\
\text { os da } \\
\text { LADC }\end{array}$ & $\begin{array}{l}\text { Favenorte } \\
\text { campus } \\
\text { Mato } \\
\text { Verde } \\
\text { (MG) }\end{array}$ \\
\hline & $\begin{array}{l}\text { Título: Direito na } \\
\text { Escola }\end{array}$ & 6 & 14 & $\begin{array}{l}\text { Acadêmic } \\
\text { os da } \\
\text { LADC }\end{array}$ & $\begin{array}{l}\text { Favenorte } \\
\text { campus } \\
\text { Montes } \\
\text { Claros } \\
(\mathrm{MG})\end{array}$ \\
\hline \multirow{3}{*}{$\begin{array}{l}\text { Cursos à } \\
\text { distância }\end{array}$} & $\begin{array}{l}\text { Título: Princípio da } \\
\text { boa-fé objetiva } \\
\text { aplicada no processo } \\
\text { penal }\end{array}$ & 4 & 12 & $\begin{array}{l}\text { Acadêmic } \\
\text { os da } \\
\text { LADC }\end{array}$ & $\begin{array}{l}\text { Remoto, } \\
\text { via } \\
\text { plataforma } \\
\text { Skype. }\end{array}$ \\
\hline & $\begin{array}{l}\text { Título: Os reflexos da } \\
\text { nova lei de liberdade } \\
\text { econômica (lei } \\
\text { 13.874/19) no direito } \\
\text { societário brasileiro e } \\
\text { no instituto de } \\
\text { desconsideração da } \\
\text { personalidade jurídica }\end{array}$ & 4 & 11 & $\begin{array}{l}\text { Acadêmic } \\
\text { os da } \\
\text { LADC }\end{array}$ & $\begin{array}{l}\text { Remoto, } \\
\text { via } \\
\text { plataforma } \\
\text { Skype. }\end{array}$ \\
\hline & $\begin{array}{l}\text { Título: Retrocesso e } \\
\text { Segurança jurídica }\end{array}$ & 4 & 10 & $\begin{array}{l}\text { Acadêmic } \\
\text { os da } \\
\text { LADC }\end{array}$ & $\begin{array}{l}\text { Remoto, } \\
\text { via } \\
\text { plataforma } \\
\text { Skype. }\end{array}$ \\
\hline \multirow[t]{2}{*}{ Eventos } & $\begin{array}{l}\text { I Jornada Acadêmica } \\
\text { de Direito } \\
\text { Constitucional }\end{array}$ & 30 & 120 & $\begin{array}{l}\text { Acadêmic } \\
\text { os do } \\
\text { curso de } \\
\text { Direito e } \\
\text { Profission } \\
\text { ais. }\end{array}$ & $\begin{array}{l}\text { Favenorte } \\
\text { campus } \\
\text { Mato } \\
\text { Verde } \\
\text { (MG) }\end{array}$ \\
\hline & $\begin{array}{l}\text { Palestra: evolução das } \\
\text { constituições } \\
\text { brasileiras }\end{array}$ & 2 & 48 & $\begin{array}{l}\text { Acadêmic } \\
\text { os do } 3^{\circ} \\
\text { período } \\
\text { de Direito }\end{array}$ & $\begin{array}{l}\text { Favenorte } \\
\text { campus } \\
\text { Mato }\end{array}$ \\
\hline
\end{tabular}

RBPG, Brasília, v.16, n.35, 2020.

Experiências 
SILVA, W. R. da; TELLES, F. F.; SILVA, N. B. da; LIMA, C. T.; MATA, M. A. da; DURÃES' M. C.

"A liga acadêmica de direito constitucional do norte de minas gerais"

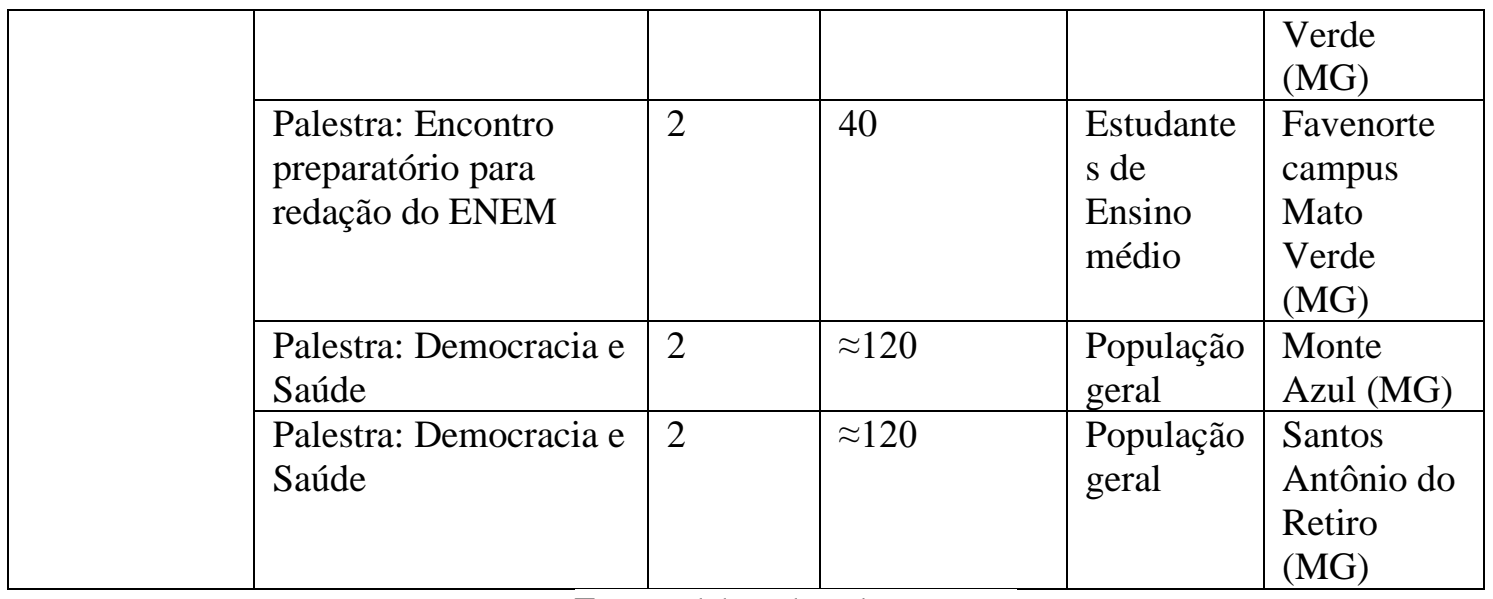

Fonte: elaborado pelos autores.

Tabela 2. Produção acadêmica original advinda de ações na LADC em seu $1^{\circ}$ ano.

\begin{tabular}{|c|c|c|}
\hline \multirow{2}{*}{$\begin{array}{c}\text { Tipo de } \\
\text { produção } \\
\text { acadêmica }\end{array}$} & \multicolumn{2}{|c|}{ Referencial da produção } \\
\cline { 2 - 3 } $\begin{array}{c}\text { Identificação } \\
\text { Produtos } \\
\text { audiovisuais }\end{array}$ & $\begin{array}{c}\text { Canal da LADC no youbute. Link de acesso: } \\
\text { Total de vídeo-aulas: 10 }\end{array}$ & $\underline{\text { https://www.youtube.com/channe }}$ \\
\hline $\begin{array}{c}\text { Resumos } \\
\text { expandidos em } \\
\text { anais de eventos }\end{array}$ & XII Fórum de Ensino, Pesquisa, Extensão e & $\underline{\text { http://www.fepeg2018.unimontes. }}$ \\
\hline & $\begin{array}{c}\text { Gestão. } \\
\text { Total de trabalhos publicados: } 4\end{array}$ & $\underline{\text { br/anais }}$ \\
& $\begin{array}{c}\text { Título: I Jornada Acadêmica de Direito } \\
\text { Constitucional }\end{array}$ & $\underline{\text { https://rev.favenorteinterd.com.br/ }}$ \\
& Total de trabalhos publicados:7 & $\underline{\text { edicoes-publicadas/ }}$ \\
\hline
\end{tabular}

Fonte: elaborado pelos autores.

No mesmo dia da cerimônia de fundação foi ofertado um minicurso sobre a escrita científica. A preocupação em oferecer esse curso se pautava na necessidade de entendimento fundamental de metodologia cientifica, com conteúdo direcionado ao início e continuidade a iniciação cientifica. A experiência mostrou um desconhecimento perturbador sobre os tópicos discutidos, ainda que já tivessem passado por disciplina básica que aborda metodologia. Dessa forma, definiu-se que o tema seria revisitado periodicamente, e outros encontros com intuito de continuidade e reforço foram planejados e executados, aproveitando da ocasião em que também seriam úteis para a futura execução do trabalho de conclusão de curso dos mesmos. Em seguida, minicursos com temas ligados à Constituição e à norma infraconstitucional ganharam espaço.

A "I Jornada Acadêmica de Direito Constitucional" ocorreu em 2018 em comemoração aos trinta anos da Constituição de 1988 e completamente organizada por

\footnotetext{
${ }^{1}$ As produções advindas da LADC podem ser identificadas localizando as autorias e coautorias, que sempre incluíram pelo menos um dos autores do presente relato
}

RBPG, Brasília, v.16, n.35, 2020. 
SILVA, W. R. da; TELLES, F. F.; SILVA, N. B. da; LIMA, C. T.; MATA, M. A. da; DURÃES' M. C.

"A liga acadêmica de direito constitucional do norte de minas gerais"

integrantes da LADC, contribuindo assim de maneira global para os demais acadêmicos e para a instituição (figura 2). O evento realizou-se em três dias, contando com seis palestrantes, oito minicursos, uma mesa redonda além de contar com exposição de trabalhos científicos na forma de resumo expandido. Foram expostos 27 trabalhos dos quais 21 foram feitos pelos alunos membros da LADC. Estima-se que 120 pessoas participaram da Jornada. Ressalta-se que foi a primeira vez que se teve um evento com exposição de trabalhos científico no curso de direito da instituição. Desses 21 trabalhos sete foram publicados nos anais de eventos da Revista Favenorte Interdisciplinar.

Figura 2. Registro da I Jornada Acadêmica de Direito Constitucional, organizada por membros da LADC, vistos na parte a) da figura, enquanto na parte b) se tem representado o ambiente onde ocorreram as palestras.

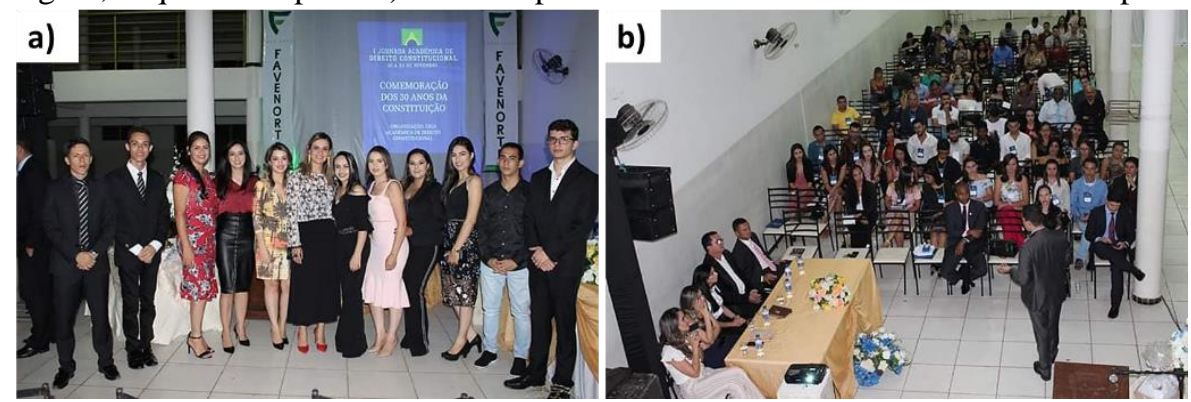

Fonte: Arquivo pessoal.

Dando efetividade à iniciação cientifica foram submetidos, aprovados e expostos quatro trabalhos na forma de resumo expandido no $12^{\circ}$ FEPEG, os quais foram publicados em anais de eventos conforme pode ser consultado na tabela 2.

Cumprindo seu compromisso com a comunidade os alunos da liga participaram do encontro preparatório para redação do ENEM promovido pela faculdade onde discutiram possíveis temas para a prova (figura 3a). O encontro contou com cerca de 40 alunos de ensino médio. Os acadêmicos da LADC em seguida foram orientados ao estudo das constituições já existentes no Brasil, culminando com apresentação pelos mesmos de palestra destinada aos seus colegas do $3^{\circ}$ período do curso. Em uma vívida interação com a comunidade foi aceito o convite pelos alunos da LADC em palestrar nas Plenárias Municipais de Saúde com o Tema "Democracia e Saúde" nas cidades de Monte Azul/MG e Santos Antônio do Retiro/MG (figura 3b). Estima-se que aproximadamente 120 pessoas participaram em cada evento. Assim, cria-se uma relação vertical entre o educador e o educando. Freire diz que "ensinar não é transferir conhecimento, mas criar as possibilidades para a sua produção ou a sua construção" (FREIRE, 2011, p. 24). Quem ensina aprende ao ensinar e quem aprende ensina ao aprender.

RBPG, Brasília, v.16, n.35, 2020. 
SILVA, W. R. da; TELlES, F. F.; SILVA, N. B. da; LIMA, C. T.; MATA, M. A. da; DURÃES' M. C.

"A liga acadêmica de direito constitucional do norte de minas gerais"

Figura 3. Registro de ações sociais promovidas pela LADC. Em a) o curso de apoio a estudantes em preparação para o ENEM. Em b) membros da LADC recebendo certificação da prefeitura por abordar aos servidores e usuários o tema "Democracia e Saúde".

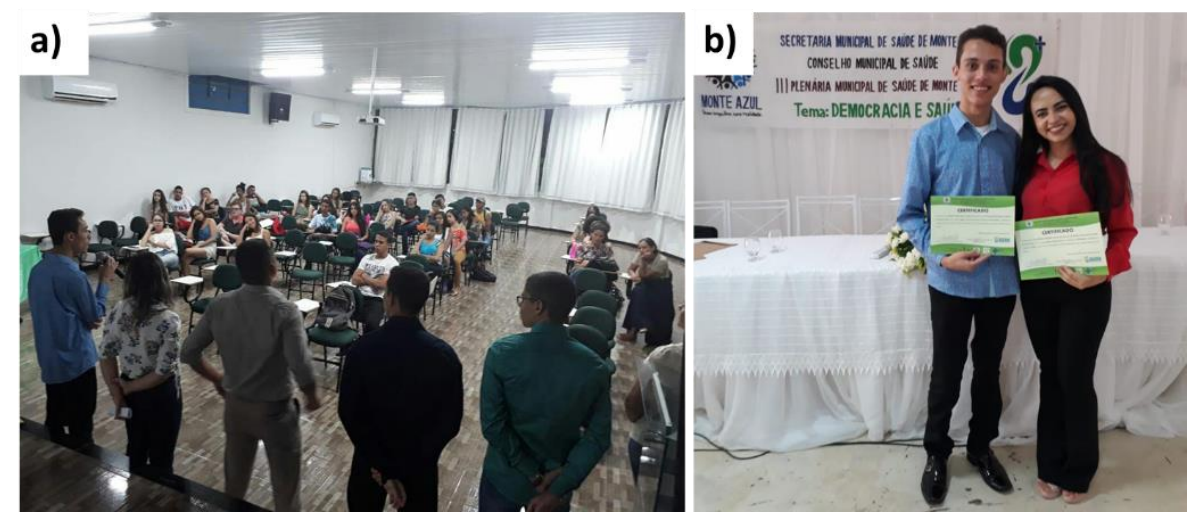

Fonte: Arquivo pessoal.

Uma atividade marcante nesse período foi a semana de atividades em Montes Claros que envolveu uma visita ao presidio regional de Montes Claros, onde os mesmos passaram uma manhã conhecendo as dependências do presidio. Em comitiva também participaram do Congresso de Direito Ambiental ofertado pela OAB de Montes Claros. E para finalizar a semana de atividades em Montes Claros participaram de minicursos e treinamentos ministrados por professores colaboradores.

Enfatiza-se que paralelamente às atividades descritas nesse tópico, corriam as reuniões quinzenais de discussão de temas definidos ao longo da semana e de orientação da iniciação científica, a qual foram divididas entre os professores coordenadores do projeto. O volume dessas reuniões é incompatível com o espaço para o relato da experiência, mostrando a intensidade e agregação da LADC na formação desses acadêmicos.

\section{CONSIDERAÇÕES FINAIS}

Relatar a experiência de um liga lotada em uma universidade pública ou mesmo em uma faculdade situada em um grande centro difere e muito de relatar uma experiência de uma liga em uma faculdade particular situada em uma cidade com pouco mais de 12 mil habitantes. Seu aluno advém quase sempre de cidades próximas e muitas vezes em situações precárias de transporte, muitos vindos diretamente do trabalho sem tempo às vezes de até mesmo se alimentarem corretamente. Nessa região, é comum que o estudante seja o primeiro da sua família a ingressar em curso superior, demonstrando que desconhecem muito do que se pode 
SILVA, W. R. da; TELleS, F. F.; SILVA, N. B. da; LIMA, C. T.; MATA, M. A. da; DURÃES' M. C.

"A liga acadêmica de direito constitucional do norte de minas gerais"

emergir da experiência ao longo do ensino superior. Dados informais apontam que nessa instituição praticamente $90 \%$ dos alunos custeiam a faculdade com programas como o FIES e o PROUNE.

Oportunizar acesso à Extensão Universitária é uma forma de romper a crise do ensino jurídico, que alinhada com o que se chamou de "educação bancária", desumaniza os acadêmicos e os transformam em instrumentalizadores de processo, repetidores e reprodutores do já posto. Ainda, proporcionar ao acadêmico uma modalidade orientada de aprendizado ativo os melhorou em autoestima. Percebeu-se com o andar das ações que os tímidos ganharam voz, que as vestimentas esportivas foram trocadas por vestimentas um pouco menos "informais", estampando o orgulho de estar ali a importância dada aquele momento e atribuição acadêmica.

O trabalho em equipe também deve ser ressaltado como experiência, corroborando com a ideia de Sócrates: "O homem é um animal social". Em tempos onde cultua o individualismo e a concorrência, a LADC mostra um descobrimento de que em equipe se produz mais e melhor. E é junto que se aprende. A interatividade pressupõe a troca, o diálogo, o fazer junto.

A iniciação cientifica também deve ser destacada. A pesquisa até então uma novidade para os alunos passa a fazer parte de suas atividades acadêmicas. Os alunos são estimulados a perceber que o mais importante na academia não é o acúmulo pragmático de saberes engessados na legislação, mas compreender que o conhecimento nos permite a ler, entender e atuar no mundo, que através do saber que se pode exercer cidadania, e que o conhecimento é uma ferramenta de luta e ascensão social.

Por fim perceberam que a sala de aula não é local para se estudar, e sim um local para se buscar direcionamento daquilo que é importante para ser estudado e esmiuçado em um mundo existente por fora dela.

\section{REFERÊNCIAS}

BOSI, A. de P. A precarização do trabalho docente nas instituições de ensino superior do Brasil nesses últimos 25 anos. Educ. Soc., Campinas, v. 28, n. 101, p. 1503-1523, dez. 2007.

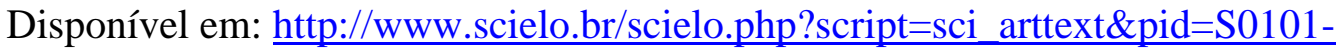
73302007000400012\&lng=en\&nrm=iso. Acesso em: 08 dez. 2019. 
SILVA, W. R. da; TELLES, F. F.; SILVA, N. B. da; LIMA, C. T.; MATA, M. A. da; DURÃES' M. C.

"A liga acadêmica de direito constitucional do norte de minas gerais"

BRASIL. Ministério da Educação. Conselho Nacional de Educação. Câmara de Educação Superior. Resolução $\mathbf{n}^{\mathbf{0}} 7$ de 18 de dezembro de 2018. 2018. Disponível em: http://portal.mec.gov.br/index.php?option=com_docman\&view=download\&alias=104251rces007-18\&category_slug=dezembro-2018-pdf\&Itemid=30192. Acesso em: 04 set. 2019.

CAPELLA, J. R. A aprendizagem da aprendizagem: uma introdução ao estudo do Direito. Belo Horizonte: Fórum, 2011.

FREIRE, Paulo. Pedagogia da autonomia: saberes necessários à prática educativa. 43. ed. São Paulo: Paz e Terra, 2011.

FORPROEX. Política nacional de extensão universitária. Manaus: FORPROEX, 2012. Disponível em: http://proex.ufsc.br/files/2016/04/Pol\%C3\%ADtica-Nacional-deExtens\%C3\%A3o-Universit\%C3\%A1ria-e-book.pdf. Acesso em: 01 ago. 2018.

LOBO, M. B. C. M. As políticas de gestão do corpo docente das IES privadas brasileiras. 2003. Disponível em: http://nupps.usp.br/downloads/docs/dt0305.pdf. Acesso em: 8 dez. 2019.

NOGUEIRA, M. D. P. (Org.). Avaliação da extensão universitária: práticas e discussões da comissão permanente de avaliação da extensão. Belo Horizonte: FORPROEX/CPAE;

PROEX/UFMG, 2013.

PAULINO, D. B. et al. WhatsApp® como recurso para a educação em saúde:

contextualizando teoria e prática em um novo cenário de ensino-aprendizagem. Rev. Bras.

Educ. Méd, v. 42, n. 1, p. 171-180, 2018. Disponível em:

https://www.scielo.br/scielo.php?pid=S0100-

55022018000100171\&script=sci_abstract\&tlng=pt. Acesso em: 16 ago. 2018.

SANTOS, B. S. A universidade no século XXI. São Paulo: Cortez Editora, 2004.

SALGADO FILHO, N. Ligas Acadêmicas: veículo de interação com a comunidade.

Maranhão: UFMA, 2007. Disponível em:

http://www.huufma.br/site/web/palavradiretor/palavra2.html. Acesso em: 15 dez. 2019.

SILVA, J. A. O constitucionalismo brasileiro: evolução institucional. São Paulo, Malheiros 2011.

SILVA, S. A.; FLORES O. ligas acadêmicas no processo de formação dos estudantes. Rev Bras Educ Méd., v. 39, n.3, p.410-25, 2015. Disponível em: https://www.scielo.br/scielo.php?pid=S0100-55022015000300410\&script=sci_arttext. Acesso em: 18 dez. 2019.

STRECK, L. Hermenêutica jurídica e(m) crise: uma exploração hermenêutica da construção do direito. 10. ed. Porto Alegre: Livraria do Advogado, 2011.

VIEIRA, R. S. O papel das tecnologias da informação e comunicação na educação a distância: um estudo sobre a percepção do professor/tutor. Revista Brasileira de Aprendizagem 
SILVA, W. R. da; TELLES, F. F.; SILVA, N. B. da; LIMA, C. T.; MATA, M. A. da; DURÃES' M. C. "A liga acadêmica de direito constitucional do norte de minas gerais"

Aberta e a Distância, v. 10, 2011. Disponível em:

http://seer.abed.net.br/index.php/RBAAD/article/view/233. Acesso em: 8 dez. 2019. 